Mariusz Kruk

Adam Mickiewicz University, Kalisz, Poland

\title{
Virtual worlds, Internet resources, motivation: The results of \\ a research project
}

\section{Introduction}

For decades, motivation has been a central area for empirical research and theoretical work within the context of foreign language learning. Moreover, there is a broad consensus among applied linguists and educators as to the fundamental role motivation plays in foreign language learning, since "motivation is often seen as the key learner variable because without it, nothing much happens" (Cohen and Dörnyei 2002: 172). In addition, identification of students' motivational predilection is crucial in foreign language classes in view of the fact that it plays a significant role in selecting "the choice of language to be learned, the kinds of activities that learners are more inclined to engage in, the types and extent of proficiency that learners expect to attain, the degree of external intervention needed to regulate learning and the extent of engagement in the long run" (Baker, Sulaiman and Rafaai 2010: 72). Beyond doubt, studying a foreign language requires a lot of effort and commitment on the part of language learners because it is a long process which can take years and can last the entire life.

It has to be remembered that computer technology is an important source of motivation for language learners. 2D/3D virtual environments, including browser-based virtual worlds, are of the most interesting and potentially useful of the new technologies for learners who can "engage in a series of purposeful educational inquiries without losing interest or sidestepping intended learning goals" (Cooke-Plagwitz 2008: 547). Thus, Cyberspace is now playing vital role in 
general education and also it is of great relevance to foreign language teaching and learning. More and more language departments, institutes as well as public and private language schools are now using virtual environments to promote and support language learning (Dalgaro and Lee 2010; Henderson, Huang, Grand and Henderson 2009; Sobkowiak 2011).

\section{Motivation in language learning}

During the past decades motivation has been considered by researchers and practitioners alike to be an important part of foreign language instruction. According to Gardner and MacIntyre (1993), motivation comprises three components: "desire to achieve a goal, effort extended in this direction, and satisfaction with the task" (Gardner and MacIntyre 1993: 3). Similarly Ellis (2008) defines motivation as "the effort learners put into learning an L2 as a result of their desire or need to learn it" (Ellis 2008: 972). In another definition of motivation Dörnyei and Ottó (1998) distinguish the dynamic part of the construct and describe it as a function of learners thinking process: "In a general sense, motivation can be defined as the dynamically changing cumulative arousal in a person that initiates, directs, coordinates, amplifies, terminates, and evaluates the cognitive and motor processes whereby initial wishes and desires are selected, prioritised, operationalised and (successfully or unsuccessfully) acted out" (Dörnyei and Ottó 1998: 65). For space limitations, it is not possible to provide all definitions of motivation in the literature (for a more comprehensive review, see Dörnyei and Ushioda 2010).

Recent studies involving L2 motivation have continued to emphasize the significance of the classroom or micro-level motivation. Instead of considering various factors related to language courses which might affect motivation, such as the teacher's influence, researchers direct their attention to task-specific issues (Dörnyei 2003: 14). In addition, task-specific motivation is one of the areas of particular interest to researchers due to the practical classroom implications of such research. Despite the fact that certain motivational characteristics are universal across learning situations and rather fixed, thus difficult to alter, L2 motivation differs substantially in relation to various learning tasks (Dörnyei 2001). In this connection, Dörnyei (2003) proposes a dynamic task processing system in order to demonstrate how task motivation is negotiated and finalized in the student. According to the researcher, the model comprises three interconnected components: (1) task execution, (2) appraisal, and (3) action control (Dörnyei 2003: 15). The first element is related to the student's commitment to task supportive learning behaviors according to the action plan previously delivered by the teacher or prepared in advance by the learner. When it comes to appraisal, it consists of students' ongoing processing of the stimuli present in the learning environment that affects their further engagement with learning outcomes. As far action control, 
it refers to an internal mechanism that supports self-regulation toward further action. In other words, task processing can be regarded as the relationship of three components:

While learners are engaged in executing a task, they continuously appraise the process, and when the ongoing monitoring reveals that progress is slowing, halting, or backsliding, they activate the action control system to 'save' or enhance the action. (Dörnyei 2003: 16)

In addition, one of the recent trends in motivation research focuses on the temporary dimension of learner motivation in the foreign language classroom. According to Dörnyei $(2001 ; 2003)$, the temporal nature of motivation is of particular significance in a domain such as language learning. In view of the fact that students are inclined to manifest a changing level of engagement even during a single class as well as they demonstrate fluctuations in motivation over a longer period of time, the researcher developed a process-oriented model of L2 motivation which categorizes the various motivational influences along a sequence of events in initiating, enacting, and sustaining motivation (Dörnyei 2003: 17-20). This model stresses the influence of a wide variety of both classroom and societal issues, such as goal setting, anticipation of success, influence of parents, teachers and peers as well as evaluation of the learning experience and attitudes toward the target language community. More specifically, the approach comprises three discrete phases: (1) preactional stage, (2) actional stage and (3) postactional stage. As for the first stage, it refers to generating motivation or choice motivation, since here learners select their goals or tasks to be followed. With regard to the second stage, it relates to executive motivation in which the generated motivation has to be actively sustained and protected. When it comes to the last stage, it is termed motivational retrospection and involves students' retrospective evaluation of how they studied. Accordingly, what learners do in this phase will determine the type of activities they might be motivated to perform. At the same time, however, the researcher cautions that the stages are linked with other motives, since learners

will be influenced, while they are still contemplating an action, by factors different from those that influence them once they have embarked on the activity. And similarly, when they look back at what they have achieved and evaluate it, again a new set of motivational components will become relevant. (Dörnyei 2003: 20)

\section{Internet resources in language learning}

The Internet offers a great deal of information, authentic or specifically prepared for ESL/EFL purposes, which can be used in foreign language classrooms for developing language skill and subsystems. 3D or 2D virtual environments, such as Active Worlds, Second Life or browser-based ones, have also become an 
important dimension of the language classroom as they offer unique, interactive and multidimensional content on the Internet. In such settings language learners can take part in games, puzzles or challenges which include 3D role playing and animated interactive environments. What is more, students in such

3-D environments often have opportunities to experience life-like social interaction while at the same time engaging in meaningful learning activities. (Cooke-Plagwitz 2008: 547)

Virtual worlds can be defined as "a synchronous, persistent network of people, represented as avatars, facilitated by networked computers" (Bell 2008: 2) or as "immersive and social environments where learners can visit relevant locations online and meet with others for real-time (voice or text) conversations" (Vickers 2010: 75). In addition, Schroeder (2008: 2) claims that virtual worlds constitute "persistent virtual environments in which people experience others as being there with them-and where they can interact with them". Thus, virtual worlds can be described as an online milieu, which lets its student-inhabitants to meet and converse with other student-inhabitants in the Cyberspace.

It should be noted, however, that the notion of a virtual world is not a new one. First virtual worlds were created in the 1970s and were connected with simulations or adventure games. They were followed by MUDs (Multi-user domains) and M00s (Multi-user domains object-oriented) and used by language teachers to teach foreign languages and intercultural understanding (Shield 2003). However, such text-based environments soon became obsolete and were replaced by more attractive and interactive worlds, as, for instance, Active Worlds. Here, a virtual reality was populated by users who could communicate with each other by text, interact with various objects and build the world around them. What is more, such virtual worlds as Active Worlds can be viewed as

the extension of chat and MOO into a non-purely-text-based environment, but one with lifelike pictures, objects, the world and special characters (avatars), which are to be chosen to impersonate the user. (Krajka 2007: 125)

According to Can (2009: 69), the implementation of virtual learning environments in the context of foreign language learning could benefit students with enriched resources and possibilities for language use as well as construction and practice. In addition, Chittaro and Ranon (2007) claim that 3D virtual environments offer a great number of benefits for language learning which involve:

1. three dimensional graphics which offer more realistic and detailed demonstration of topics;

2. the possibility of analyzing the same issues or phenomena from different perspectives;

3. easier and more motivating interaction with another student when compared with interaction with a coursebook or a computer; 
4. the presence of virtual teachers or other animated lifelike characters, which may have a positive impact on learners' perception of the learning experience;

5. the opportunity of collaborating with one or more virtual companions (or avatars).

On the other hand, however, virtual worlds have some drawbacks which may include:

1. difficulties in navigation and in the use of 3D interfaces;

2. teachers' lack of experience or difficulties in classroom use;

3. students' disappointment with the lack of realism of some virtual worlds;

4. cost of hardware (Chittaro and Ranon 2007).

\section{The study}

\subsection{Background to the study}

The data was collected over a three-week period. It involved four English lessons. The classes were based on Internet and traditional materials. The overall aim of the study was to investigate the impact of Internet resources and a browserbased virtual world on the subjects' motivation. For the purpose of this study, motivation was defined in the terms suggested by Crookes and Schmidt (1991: 98-502), Peacock (1997: 145-146) and Pawlak (2012: 254-255): interest in and enthusiasm for the resources used in the classroom, perseverance in learning as well as levels of concentration and enjoyment.

\subsection{Research questions}

The present study was guided by the following research questions:

1. Were Internet resources and the virtual world more motivating for students than traditional coursebook materials?

2. Did levels of the students' motivation change in the course of a single class? If yes, how?

3. Did levels of the students' motivation change in the course of a series of lessons? If yes, how?

4. How were different types of resources responsible for these fluctuations?

\subsection{Participants}

Thirteen third grade students of Polish senior high school participated in the study. The analysis of the data obtained by means of the background questionnaire revealed that the subjects had been learning English for 8.46 years. The grade 
point average in English at the end of the second grade amounted to 2.38 on a 0-6 scale, which shows that the class consisted of rather weak students. What is more, only 38\% students admitted to attending some additional courses or tutorials; however they were mainly limited to extra school lessons the purpose of which was to prepare the learners for their final English exam. In addition, the students reported some out-of-class exposure to the target language, however it was mainly limited to watching English movies (dubbed or with Polish subtitles-69\%) and listening to English music (62\%). Only 4 students (31\%) said that they read in English (e.g. books, articles, Internets pages, etc). All subjects stated that they had access to the Internet at home; however, they used it occasionally to study English. It is also interesting to note that the majority of the subjects (84.6\%) regarded grammar to be to be the most difficult for them to study.

\subsection{Instructional treatment}

The first lesson started with the multimedia presentation of the English second conditional. The teacher explained its use and form as well as provided relevant examples. This was followed by a series of online activities created by the teacher by means of the computer program Hot Potatoes and an interactive exercise on the Internet. The activities were of the following type: matching, translation and multiple choice exercise (e.g. http://www.anglik.neostrada.pl/virtual.worlds/ second.conditional.match.1.htm, http://web2.uvcs.uvic.ca/elc/studyzone/410/ grammar/2cond1.htm). Next, the students were given handouts which contained several sentences with gaps to be completed with provided verbs. The activity was checked by the teacher who asked at random several students to read their answers. Finally, the subjects were given a homework assignment which required the learners to complete several sentences by typing the correct form of given verbs (http://web2.uvcs.uvic.ca/elc/studyzone/410/grammar/2cond2.htm). During the second lesson the students were asked to perform a sequence of online activities. These were multiple choice exercises created by the teacher (e.g. http://www.anglik.neostrada.pl/virtual.worlds/second.conditional.quiz.1.htm) and a gap completion exercise (http://testyourenglish.pl/test-76). After that, the learners were given handouts which contained five situations and words in order to write sentences in the second conditional (e.g. Paul has asked you to go to a jazz concert. You don't like jazz so you're not going with him. (I go / with you / if I / like jazz)). Next the activity was checked by the teacher who asked at random several students to read the answers. When it comes to the third lesson, the subjects were first requested to do one multiple-choice activity and two fill-in-the-gaps exercises (e.g. http://www.anglik.neostrada.pl/virtual.worlds/second.conditional.quiz.3.htm, http://www.anglik.neostrada.pl/virtual.worlds/second.conditional.cloze.2.htm) and then the learners were asked to log on to the virtual world Yoowalk (http://www.yoowalk. $\mathrm{com} /$ ). The students were provided with a handful of example questions in the second 
conditional and encouraged to use them in order to talk to the residents of this virtual world. During the last lesson the students completed three online activities. These were one multiple choice and two gap-fill exercises (http://www.englisch-hilfen.de/ en/exercises/if_clauses/type_2_mix3.htm, http://www.englisch-hilfen.de/en/exercises/ if_clauses/type_2_statements.htm and http://www.englisch-hilfen.de/en/exercises/if_ clauses/type_2_negation.htm). Next, the students logged on to Yoowalk and conducted a questionnaire among its residents. In order to accomplish the task they were requested to use the questions from the previous class or invent their own ones as well as to answer them paying attention to the form and meaning. It should be noted that specific amount of time was allocated to each of the exercises and the detailed description of the lessons is presented in Table 1.

Table 1. Lessons, procedures and times

\begin{tabular}{|c|c|c|}
\hline Lessons & Procedure & $\begin{array}{l}\text { Time/minutes } \\
\text { (approximately) }\end{array}$ \\
\hline \multirow{5}{*}{1} & Organization / Checking homework assignment & $1-10$ \\
\hline & Second conditional (multimedia presentation) & $11-20$ \\
\hline & Online activities (chosen and/or created by the teacher) & $21-30$ \\
\hline & Traditional activity (chosen and/or created by the teacher) & $31-40$ \\
\hline & Conclusion & $41-45$ \\
\hline \multirow{4}{*}{2} & $\begin{array}{l}\text { Organization / Revision and checking homework } \\
\text { assignment }\end{array}$ & $1-10$ \\
\hline & Online activities (chosen and/or created by the teacher) & $11-30$ \\
\hline & Traditional activity (chosen and/or created by the teacher) & $31-40$ \\
\hline & Conclusion & $41-45$ \\
\hline \multirow{4}{*}{3} & $\begin{array}{l}\text { Organization / Revision and checking homework } \\
\text { assignment }\end{array}$ & $1-10$ \\
\hline & Online activities (chosen and/or created by the teacher) & $11-25$ \\
\hline & $\begin{array}{l}\text { Virtual world activities (talking with the residents of the } \\
\text { virtual world) }\end{array}$ & $26-40$ \\
\hline & Conclusion & $41-45$ \\
\hline \multirow{4}{*}{4} & $\begin{array}{l}\text { Organization / Revision and checking homework } \\
\text { assignment }\end{array}$ & $1-10$ \\
\hline & Online activities (chosen and/or created by the teacher) & $11-20$ \\
\hline & $\begin{array}{l}\text { Virtual world activities (conducting a questionnaire in the } \\
\text { virtual world) }\end{array}$ & $21-40$ \\
\hline & Conclusion & $41-45$ \\
\hline
\end{tabular}


It has to be added that the second, third and the fourth lesson commenced with revisions of the previously acquired information related to the second conditional and checking homework assignments. In addition, each class finished with giving the students relevant homework assignments.

\subsection{Data collection instruments and analysis}

The following data collection instruments were used in the course of the present study: the background questionnaire, interest grids, overall assessment of lessons questionnaire, the evaluation sheet and learners' logs. The decision to ask the learners to fill in the background questionnaire stemmed from the conviction that such information concerning the students' attitudes, their learning history and type of exposure might prove useful while interpreting the results of the research project. With regard to the students' interest grid, its purpose was to measure the subjects' level of engagement and interest in classes every five minutes (i.e. seven times). They were provided with a scale ranging from 1 ('I am not engaged and interested in activities at all') to 7 ('I am engaged and interested in activities completely'). The instrument was a modified version of a grid used by Pawlak (2012). The internal consistency reliability of the tool was established on the basis of the results obtained for the first class by calculating Cronbach's alpha which turned out to be high $(\alpha=.88)$. When it comes to the overall assessment of the lesson questionnaire, the purpose of this instrument was to assess the value of the activities used in each lesson. At the end of each lesson the students were asked to indicate their impressions on a semantic differential scale (a 1-7 scale) containing seven items such as exciting/dull, unsatisfying/satisfying or absorbing/ monotonous. The instrument was a modified version of a survey used by Peacock (1997) and Pawlak (2012). The value of Cronbach's alpha for the first class was high $(\alpha=.90)$, which indicates the tool's appropriate internal consistency reliability. As for the qualitative data they were collected by means of the learners' logs. The main purpose of the logs was to obtain information on the students' perceptions and impressions of the activities and classes as diaries can provide the researcher information about the process of learning that might be otherwise difficult to obtain (Gass-Mackey 2007). The logs were produced by the students electronically in the form of text documents and sent to the teacher by email after each lesson. Yet another data collection tool was the evaluation sheet that aimed at obtaining the learners' opinions on the lessons and the activities. It was filled out anonymously by the subjects after the four classes.

It should be noted that the instruments of the data collection were piloted before the study went under way on a comparable class of senior high school students. In addition, the research instruments were written and presented to the subjects in Polish so as to avoid any potential misunderstandings. The collected data were subjected to quantitative and qualitative analyses. The former involved computing the mean score, the percentages of the mean score and the standard 
deviation. Furthermore, the statistical significance of the differences in the means was established by means of repeated measures ANOVA. As for the qualitative data they were obtained by means of the students' logs. The analysis involved reading the documents several times and looking for 'recurring regularities' (Patton 2002: 465). It should be noted that a criterion was used that the same word, expression or a theme should be mentioned by the learners at least twice.

\section{Results}

Figure 1 demonstrates the changes in the students' motivation manifested over the course of the four classes and every five minutes. The patterns show that at the beginning of each lesson the level of the subjects' motivation never amounted to less than 4.80 , but at the same time, it never exceeded 5 on a 1-7 scale. The reported levels of motivation always rose from minute 10 to minute 15 of each lesson. What is more, in the middle of each class, the learners' motivation concentrated above 5.50 , and not once surpassed the six-point-threshold. In addition, in the second half of most of the classes the degree of the students' motivation continued to rise up (Lessons 3 and 4) or to fall down (Lesson 1) for some time. It is interesting to note that the learners' motivation decreased in the final minutes of the first, second and fourth classes, the only exception being Lesson 2 . Here the subjects' motivation increased quite dramatically at the end of the class. Generally speaking, the results demonstrate that the students' motivation was in a constant state of flux. It has to be noted, however, that the differences in the mean scores between different time points of the four lessons were not statistically significant $(p>0.05)$.

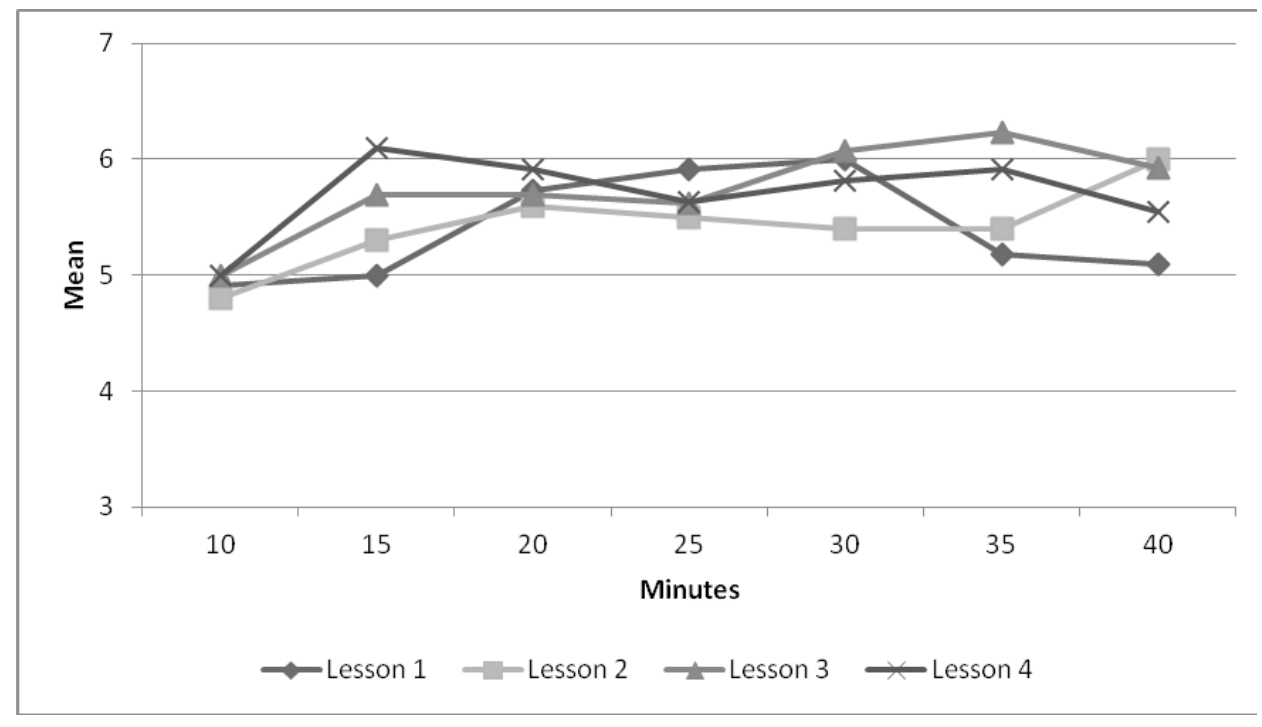

Figure 1. Changes in interest and engagement in the four lessons 
When it comes to the changes in motivation during the first lesson, it was quite stable in the first several minutes of the class (see Figure 1). Then it kept increasing for about 15 minutes during which the students were requested to do some online activities. However, in the final minutes of the lesson, in which the learners were asked to perform a traditional exercise, the students' level of motivation returned to its initial levels. As for the second lesson, the reported level of motivation was relatively stable, although an increase at the beginning and the end of this class was observed. It has to be noted that the increased in motivation coincided with the parts of the lesson dedicated to some Internet activates (minute 10-30) and a coursebook one (minute 31-40). Thus, it is interesting to note that both online and traditional activities were of great interest to the subjects. As for the third lesson, two increases in the students' motivation were observed; one in the first part of the class and the other in the second one. It has to be noted, however, that the second half of this class was reported to be the most motivating of all, since the students' motivation level reached the value of 6.23. One way to account for the finding is that the second half of the lesson was conducted in the virtual world Yoowalk which constituted a new and perhaps more stimulating learning environment for the students. As regards the fourth class, the beginning of it showed a sudden increase in motivation by 1.09 from minute 10 to 15 . Then the students manifested various levels of motivation at different points in time, although it was rather stable until the end of the lesson. Such pattern might be explained by the fact that this lesson in its entirety was dedicated to practicing the structure in question by means of Internet activities and the virtual world. The gradual drop in the students' motivation, its fluctuations and the final decrease in it might be related to the difficulty of the activities, their attractiveness or the fact that the novelty of the instruction might have worn off and some students might have become simply bored with the lesson.

Table 2. Total mean scores, percentages and standard deviations of the four classes

\begin{tabular}{lrcrr}
\hline & Lesson 1 & Lesson 2 & Lesson 3 & Lesson 4 \\
\hline Mean & 5.40 & 5.43 & 5.75 & 5.70 \\
$\%$ & 77.14 & 77.57 & 82.14 & 81.43 \\
Standard deviation & .46 & .36 & .40 & .36 \\
\hline
\end{tabular}

Finally, a few words are in order on how the students' interest and engagement manifested itself in the total mean scores over the course of the four classes. As can be seen from Table 2, the reported motivation increased slowly from Lesson 1 to Lesson 2 and then increased sharply in Lesson 3 by the value of 0.32 when compared with Lesson 2. A small drop in the level of motivation by a minute 0.05 was detected in Lesson 4 when compared with Lesson 3. In addition, the third and the fourth classes were the most interesting and engaging for the learners. It should be noted, however, that the differences in the total mean scores did not 
prove to be statistically significant $(p>0.05)$. As stated earlier in this paper, during these lessons the learners had the opportunity to perform online activities and use one of the available online virtual worlds. Thus, this finding could be interpreted as testifying to the appealing nature of such digital activities and browser-based virtual worlds, which also provide the possibility to exist and communicate with other people in this digital dimension. In addition, as the data included in Table 2 demonstrate, the standard deviations were quite similar in the second, third and the fourth lessons which can be taken as evidence that the treatment lessened the degree of individual variation between the subjects.

When it comes to the students' overall assessment of the four classes, they were high with the mean scores surpassing or approaching 6.00 points on a 1-7 scale (see Figure 2 and Table 3). However, a closer investigation of Figure 2 reveals that the first lesson was perceived by the students to be the most enjoyable, meaningful and appealing with the mean scores in each case exceeding 6.50 on a 1-7 scale. On the other hand, the learners considered Lesson 4 to be the least interesting, enjoyable, meaningful, exiting and absorbing of all the classes, although even in this case the mean scores for each item were pretty high with the lowest equaling 5.30. What also stands out from Figure 2 is that the attractiveness was the only item of all to reach the lowest mean scores (the average equaled 5.49).

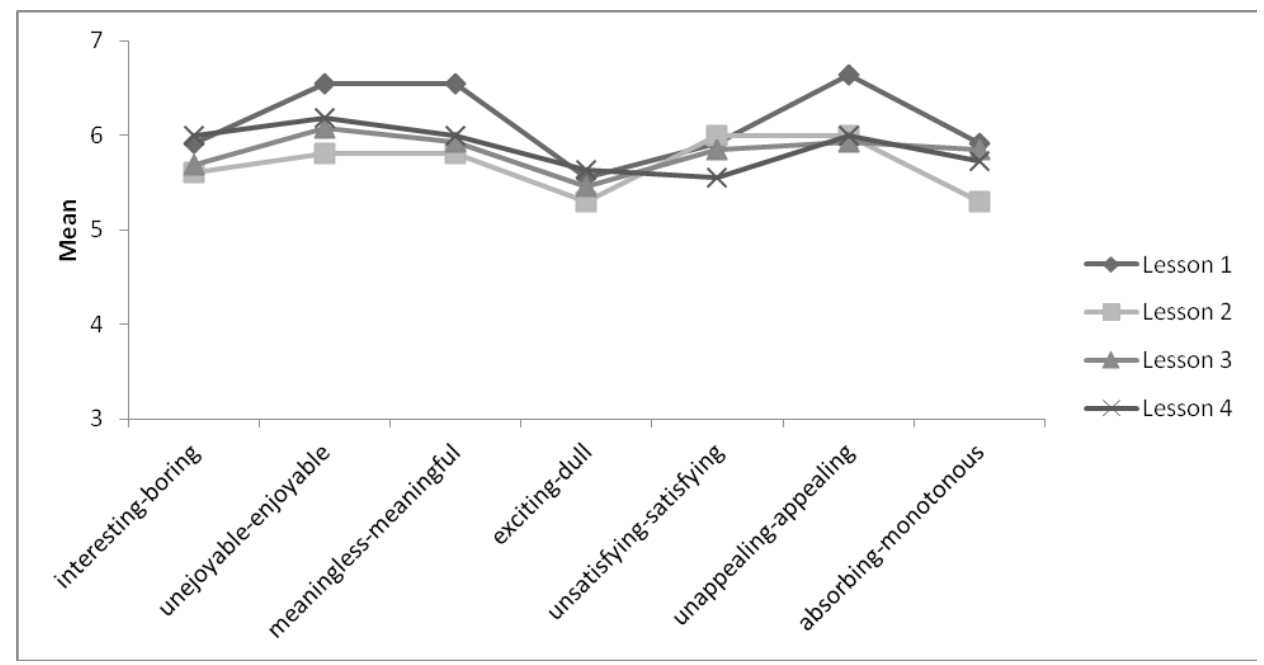

Figure 2. Students' overall evaluation of the lessons

Table 3. Total mean scores, percentages and standard deviations for the overall evaluation of the four lessons

\begin{tabular}{lrrrr}
\hline & Lesson 1 & Lesson 2 & Lesson 3 & Lesson 4 \\
\hline Mean & 6.14 & 5.69 & 5.82 & 5.87 \\
$\%$ & 87.71 & 81.29 & 83.14 & 83.86 \\
Standard deviation & .43 & .30 & .20 & .23 \\
\hline
\end{tabular}


As can be seen from Table 3, the first lesson was assessed by the subjects as the best one while the second class received the lowest mean score. Such results are difficult to explain when the students' evaluation of the lessons is juxtaposed with the reported motivation of the four classes. This is because Lesson 1 was the least motivating for the participants of the study. It is also interesting to note that Lesson 3 and Lesson 4 were both almost equally evaluated by the students as well as they turned out to be equally motivating for them. A possible explanation for these findings might be related to the nature of the lessons; the first two were conducted by a combination of online and traditional materials, the third and the fourth classes were entirely based on Internet resources and the virtual world.

The qualitative analysis of the data gathered by means of the learners' logs and the evaluation sheet showed that the students enjoyed the classes and the Internet activities. They also liked the virtual world they inhabited and the opportunity to practice the structure there. The students also felt they were making progress in using the second conditional. Some learners claimed that this was due to the fact that they could work independently of the teacher. This is evidenced by the following comments gleaned from the learner's logs:

- I think that the lessons helped me a lot. I was able to understand and memorize the basics of the second conditional. I did the exercises without any problems and now I can proudly say that I did them all correctly.

- Thanks to this virtual world I learned how to use the second conditional in practice.

- I like very much the fact that there is a variety of exercises and that several lessons are devoted to the same topic.

- I liked the lessons a lot and I enjoyed the computer activities in particular. I did them on my own and I could check them myself. Thanks to it I learned a lot.

Despite the fact that some activities the students were required to perform constituted quite a challenge for at least several learners, they found a way of dealing with the problems they encountered by using information available on the Internet or by collaborating with other students. In addition, the subjects claimed that they were able to learn a lot by means of feedback they received while doing online activities. The following three excerpts exemplify the findings:

- The most difficult thing to me is the past participle of irregular verbs. But I used irregular verb tables available on some Internet pages.

- I think that the most difficult was the activity in which I had to answer some questions, because I had to answer them in full sentences and also add some other information. But I have to say that I didn't have many problems with that (...) In case of problems I could always ask a friend or the teacher.

- (...) I learned a lot during the lessons. I could check the answers while doing the exercises at the computer and thus I knew what I did wrong.

A further interesting and useful finding was related to the fact that both online activities and the exercises performed in the virtual world were considered by the 
subjects to be almost equally motivating for them. In addition, the subjects were quite unanimous in claiming that they enjoyed both the use of online exercises and the virtual world. This is visible in the following comments:

- Generally all of them but those from the Internet most (...) because we could correct our own mistakes. I didn't like the paper exercises very much (...)

- (...) quizzes and gap filling exercises because I always managed to do them correctly. There were different types of exercises and they weren't difficult for me.

- (...) when we asked and answered each other questions [in the virtual world] but it wasn't always easy. This exercise allowed me to understand the second conditional (...).

\section{Discussions and conclusions}

The analysis of the data revealed that, overall, the subjects reported high levels of motivation over the course of the four lessons and also during each lesson. It has to be noted, however, that the students showed more interest and engagement when online activities and the virtual world were applied. This is not to say, of course, that traditional coursebook activities were not at all motivating for the learners, but, rather, that they were always part and parcel of English lessons. It should be noted, however, that the paper-based exercises proved to be more susceptible to changes in motivational intensity. Conversely, when the students performed online activities fluctuations in the level of motivation were less pronounced. In addition, the motivational nature of online tasks is also visible in the students comments obtained by means of the questionnaires and the learners' logs. The subjects claimed that they enjoyed working in the digital environment and using the item in question in practice while being in the virtual world. The students liked the idea of being able to solve grammar activities on their own without waiting for the teacher to check the answers and provide explanations. Also, the learners appreciated the fact that they felt they were making progress from one lesson to another.

In addition, the results of the study provided some empirical evidence that the degree of motivation changed not only from longer periods of time (i.e. from lesson to lesson) but also within a single class (i.e. from one activity to another). It should be noted that such fluctuations could be the direct outcome of the treatment and the tasks the subjects were requested to perform. As has already been mentioned, the use of the virtual world resulted in increased motivation in the second half of the third and fourth lessons. Moreover, a variety of online activates the students did on their own in the first half of the second, third and the fourth lessons might have also contributed to increased motivation. Conversely, when the students performed analog (i.e. traditional) activities their interest in 
lessons was weaker, the only exception being the last five minutes of the second lesson. A possible explanation of this finding might be related to the fact that after a series of Internet activities the students' finally began to understand the structure better and when they were asked to do a coursebook activity they were motivated to perform it. This was observed by the teacher who asked at random several students to read the answers which turned out to be correct in most cases. What also merits a few words of explanation at this point is the sharp growth in the subjects' motivation observed in the middle of the first class and then a sudden drop in it. In all likelihood, this increase can be ascribed to the fact that the learners started to work at the computer which required them to perform two interactive exercises on the Internet and then they were asked to solve a traditional activity. This, again, may testify to the appealing nature of digital resources over traditional ones.

In the light of such findings, a possible conclusion can be drawn that Internetbased tasks may be motivating, at least when administered in the form and context characteristic of the present study. Thus, it has to be remembered that there is no guarantee that all learners can benefit from such activities and the fact that they might be useful primarily in the case of senior high school students. It seems that these results should not discourage researchers from embarking on further investigation of the value of Internet-based tasks, and, in particular, virtual world ones. Quite to the contrary, since the study offers some evidence that onlinedriven tasks may have a positive impact on motivation; further research seems to be necessary to achieve a more comprehensive picture of theirs strengths and liabilities.

There are a few weaknesses of this study that should be considered. A major limitation dictated by the school policy and curriculum considerations was the relative shortness of the treatment. This was also responsible for some other limitations. First, the relatively small number of participants reduces the generalizability of the findings. Second, a control group should be involved in the study. Another important limitation is related to the fact that the present author was also the subjects' regular English teacher. This could have resulted in motivating the students to a greater extent to study the structure in question. What is more, it cannot be ruled out that the overall high levels of the reported motivation might have resulted from the fact that some subjects tried to please the teacher with their answers rather than provide a true account of the conducted classes and activities. Finally, subsequent research should be conducted with other types of learners and in different instructional settings. All of these limitations should be eliminated in future studies to achieve a better picture of the efficacy of such instruction.

Since one of the aims of this kind of research is to offer practical implications for language teachers, a list of such guidelines can be summarized as follows: 
1. Teachers should employ modern technology in their lessons, and, in particular, virtual worlds for the reason that they introduce an element of novelty and thus make students more interested in learning the target language.

2. When it comes to planning and implementing grammar-based lessons, there is a place for a combination of both analog (traditional) and digital (innovative) ways to motivate students.

3. Lessons should be conducted in such a way that students are provided with opportunities to work on their own in less controlled conditions.

4. An inevitable corollary of the preceding point is that teachers should also try to foster learner autonomy in view of the fact that motivation and autonomy seem to be interrelated (Benson 2007; Murray, Gao and Lamb 2011).

5. It is necessary to realize that motivation is not a one-shot affair and, thus, teachers should devote a lot of time and effort to interest and engage students in learning the target language.

In addition, taking into account the unique characteristics of each local teaching-learning setting, these recommendations can only be provisional and tentative, and, therefore, viewed as proposals to facilitate classroom practices rather than prescriptions to be obeyed at any price.

\section{References}

Baker, K.A., Sulaiman, N.F., Rafaai, Z.A.M. 2010. "Self-determination theory and motivational orientations of Arabic learners: A principal component analysis" GEMA OnlineTM Journal of Language Studies 10(1): 71-86.

Bell, M.W. 2012. Toward a definition of "Virtual Worlds. Journal of Virtual Worlds Research 1(1). Accessed November 20, 2012.

Benson, P. 2007. Autonomy in language teaching and learning. Language Teaching 40: 21-40.

Chittaro, L. Ranon, R. 2012. Web3D technologies in learning, education and training: Motivations, issues, opportunities. Computers \& Education 49(1). Accessed November 23, 2012.

Cohen, A. Dörnyei, Z. 2002. Focus on the language learner: Motivation, styles and strategies. In N. Schmitt (Ed.), An introduction to applied linguistics, 170-190. London: Arnold.

Cooke-Plagwitz, J. 2008. New directions in CALL: An objective introduction to Second Life. CALICO Journal 25(3): 547-557.

Crookes, G. Schmidt, R.W. 1991. Motivation: Reopening the research agenda. Language Learning 41(4): 469-512.

Dalgarno, B., Lee J.W.M. 2010. What are the learning affordances of 3-D virtual environments? British Journal of Educational Technology 41(1): 10-32.

Dörnyei, Z. 2003. Attitudes, orientation, and motivations in language learning: Advances in theory, research, and applications. Language Learning 53: 3-32.

Dörnyei, Z. 2001. "New themes and approaches in second language motivation research." Annual Review of Applied Linguistics 21: 43-59.

Dörnyei, Z., Ushioda, E. 2010. Teaching and Researching: Motivation. Pearson United Kingdom. Dörnyei, Z., Istvan, O. 1998. Motivation in action: A process model of L2 motivation. Working Papers in Applied Linguistics Vol. 4, 43-69. Thames Valley University. 
Ellis, R. 2008. The Study of Second Language Acquisition. Oxford: Oxford University Press.

Gardner, R.C., MacIntyre P.D. 1993. A Student's contributions to second-language learning: Part II: Affective variables. Language Teaching 26: 1-11.

Gass, S.M., Mackey A. 2007. Data elicitation for second and foreign language research. Mahwah, New Jersey: Lawrence Erlbaum.

Henderson, M.H., Scott H.G., Lyn H. 2009. "Language acquisition in Second Life: Improving selfefficacy beliefs." Paper presented at ASCILITE Auckland, New Zealand, December 2009.

Krajka, J. 2007. English language teaching in the Internet-assisted environment. Lublin: Wydawnictwo Uniwersytetu Marii Curie-Skłodowskiej.

Murray, G., Gao, X.A., Lamb, T. 2011. Identity, motivation and autonomy in language learning. Bristol: Multilingual Matters.

Patton, M.Q. 2002. Qualitative evaluation and research methods (3rd edition.). Newbury Park, CA: Sage.

Pawlak, M. 2012. The dynamic nature of motivation in language learning: A classroom perspective. Studies in Second Language Learning and Teaching 2(2): 249-278.

Peacock, M. 1997. The effect of authentic materials on the motivation of EFL learners. ELT Journal 51: 144-156.

Shield, L. 2003. MOO as a language learning tool. In F. Uschi (Ed.), Language learning online: Towards best practice, 97-122. Lisse: Swets \& Zeitlinger.

Sobkowiak, W. 2011. "Happiness I hadn't felt before", czyli nauka języków obcych w drugim życiu." In M. Pawlak, B. Wolski (Eds.), Wykorzystanie nowoczesnych technologii w dydaktyce języków obcych, 123-130. Konin: Wydawnictwo UAM PWSZ w Koninie.

Vickers, H. 2010. VirtualQuests: Dialogic language learning with 3D virtual worlds, CORELL: Computer Resources for Language Learning 3: 75-81. 